\title{
O SISTEMA DE PRECEDENTES E A LIBERDADE DE DECIDIR
}

\author{
Vinícius Vilela dos Santos* \\ Luiz Fernando Bellinetti**
}

\section{Resumo:}

O objetivo deste trabalho é verificar os impactos que as reformas no sistema jurídico trouxeram para a liberdade decisória, perpassando pela imprescindível análise de temas do sistema processual. Mediante pesquisa bibliográfica e descritiva, parte-se de conceitos gerais à análise da implementação e dinâmica do sistema de precedentes como ferramenta para alcançar segurança jurídica, uniformização e estabilização da jurisprudência. Utilizando-se do método dedutivo, demonstra-se como assegurar a integridade, coesão e coerência do direito, apresentando a relevância prática do tema na compreensão dos efeitos da globalização em nosso sistema jurídico e no impacto que os precedentes trouxeram para a liberdade de decidir.

Palavras-chave: Globalização; Sistema Jurídico Brasileiro; Reformas; Sistema de Precedentes; Liberdade de decidir.

\section{THE PRECEDENT SYSTEM AND THE FREEDOM TO DECIDE}

\begin{abstract}
:
The objective of this work is to verify the impacts that reforms in law cause problems for decisive freedom, going through the indispensable analysis of subjects of the procedural system. Through bibliographic and descriptive research, we start from general concepts for analyzing the implementation and use of the precedent system as tool to achieve legal security, standardization and stabilization of jurisprudence. Using the deductive method, demonstrate how to guarantee the integrity, cohesion and coherence of the law, display statistics of practical practices on the effects of globalization on our legal system and impact on the problems for freedom of decision.
\end{abstract}

Keywords: Globalization; Brazilian legal system; Reforms; Precedent system; Freedom to decide

\section{Introdução}

Diante de um cenário contemporâneo de avanço tecnológico, a globalização tem trazido diversas mudanças no modo das pessoas e sociedade se relacionarem, desde o âmbito econômico, social, cultural, o que traz severas repercussões aos sistemas jurídicos de cada país.

\footnotetext{
* Mestrando em Direito Negocial na Universidade Estadual de Londrina - UEL. Advogado. Especialista em Direito Civil e Processual Civil pela Toledo Prudente Centro Universitário. Especialista em Direito Empresarial e Direito Tributário pela Toledo Prudente Centro Universitário. Professor da Faculdade de Presidente Epitácio/SP.

Doutor em Direito pela Pontifícia Universidade Católica de São Paulo. Professor da Universidade Estadual de Londrina.
} 
Nesse sentido, o objetivo deste trabalho é justamente de verificar os reflexos da globalização para o arcabouço jurídico brasileiro, analisando, especificamente, o impacto do sistema de precedentes na liberdade decisória.

Com isso, o estudo trata esse novo cenário jurídico e institucional construído pelos efeitos da globalização, analisando as reformas levadas a efeito no sistema jurídico pátrio, especialmente as reformas processuais, direcionadas em grande parte pelo Documento Técnico 319 do Banco Mundial, cujo objetivo era de promover o desenvolvimento econômico e transformar o Poder Judiciário num garantidor dos princípios econômicos a serem implementados nos Estados alvos, e estimular o acesso à justiça.

Nesse sentido, dentre todas as reformas, mostra-se pertinente analisar o sistema de precedentes estabelecido pelo Código de Processo Civil de 2015, a qual é desenvolvida mediante pesquisa bibliográfica e descritiva, demonstrando ser um importante instrumento para assegurar a integridade, coesão e coerência do direito.

Além disso, utilizando-se do método dedutivo, serão analisados, ainda, os reflexos dessas modificações no ordenamento jurídico pátrio, especialmente, no que diz respeito à implantação dos precedentes vinculantes e os impactos desta ferramenta na liberdade decisória.

\section{A construção de um novo cenário jurídico diante da globalização}

A partir da segunda metade do século XX, houve uma grande expansão tecnológica, notadamente na área de comunicação com a popularização da internet, que causou uma modificação das fronteiras preexistentes, alimentando a globalização econômica.

A globalização gerou uma integração dos mercados, e, mais do que isso, tem causado desdobramentos institucionais e jurídicos, modificando o papel do Estado neste novo cenário, especialmente pelos contextos cada vez mais complexos e mutáveis, surgindo a necessidade de uma releitura do sistema jurídico e das fontes do direito.

O fenômeno da globalização fez surgir a chamada sociedade mundial, que apresenta conflitos que, embora sejam internos, podem repercutir para além das fronteiras geográficas. Além disso, a massificação da sociedade também exige uma nova forma de solução dos conflitos. 
Verifica-se que esse fenômeno torna muito difícil a manutenção dos padrões políticos, econômicos e jurídicos que direcionavam as sociedades, uma vez que há uma profunda alteração de fatores como democracia e tutela jurisdicional, fragilizando o conceito de soberania, de forma que é imprescindível a busca por alternativas democráticas para equacionar essas situações, desenvolvendo instrumentos para enfrentar os problemas que derivam desse fenômeno, pois, a sobrevivência da humanidade depende disso (BELLINETTI, 2017, p. 85-86).

Num contexto de mercados altamente globalizados, de internacionalização das cadeias produtivas, de conectividade mundial e territorialidade difusas, bem como de erosão das fronteiras entre o público e o privado, tem-se utilizado duas estratégias. A primeira exige uma revisão das políticas legislativas tradicionais e uma redefinição das fontes formais de direito, uma vez que implica em um severo enxugamento do ordenamento jurídico e consequente estímulo à sociedade para que desenvolva meios de autocomposição. A segunda estratégia consiste em proporcionar aos atores econômicos e sociais condições de discutir entre si, e assim, tentar definir de modo consensual, o conteúdo das normas. (FARIA, 2017, p. 110-112)

O objetivo de ambas estratégias é desvincular o Estado de suas funções controladoras e reguladoras no âmbito econômico, levando-o a substituição da tradicional rigidez hierárquica de códigos e leis pela flexibilidade e diversidade normativa, e ao pluralismo jurídico, ou seja, ao advento de diferentes ordens normativas nos mesmos espaços geopolíticos. (FARIA, 2017, p. 112-113)

Diante disso, o direito não pode mais ser visto como uma unidade, e a cada dia que passa o pluralismo jurídico tem se mostrado uma realidade, e pode ser visto de forma muito abrangente, não só abrangendo os arcabouços jurídicos dos países, mas também de sistemas jurídicos não-estatais, como é o caso, por exemplo, da Lex mercatoria.

Este contexto fez com que o direito internacional privado perquirisse a adoção de um método para uniformização de normas, a fim de garantir maior segurança jurídica nas relações comerciais que ultrapassem as fronteiras geopolíticas.

O liberalismo, por sua vez, tem se inclinado para a defesa da atividade econômica dos agentes sociais, priorizando a atividade econômica como um instrumento de consolidação dos ideais políticos de uma sociedade liberal, que é regida pela liberdade de mercado. (RAMOS, 2005, p. 230) 
E, justamente neste aspecto, que o liberalismo político contemporâneo se volta a ocupar questões imprescindíveis à filosofia política, a exemplo da ideia de justiça, da legitimidade do governo e do poder político, as vantagens da democracia e, acima de tudo, as possibilidades da liberdade diante das sociedades modernas plurais e diferentes. (RAMOS, 2005, p. 230)

Não obstante, o que tem se visto é uma expansão do common Law, com o escopo de se uniformizar o direito na esfera global, sobretudo impondo aos tribunais um intercâmbio jurisprudencial.

Digno de nota que duas das principais características do sistema do common Law é justamente o individualismo, tendo em vista a garantia de direitos subjetivos ao indivíduo, e o liberalismo, que assegura a constituição de mecanismos para proteger o indivíduo contra o Estado.

Neste sentido, o sistema jurídico brasileiro tenta se adequar às mudanças sociais, ajustando seus conceitos, suas fontes de interpretação, e até mesmo inserindo no arcabouço novos institutos, a exemplo do sistema de precedentes vinculantes.

Embora em outros países se utilize comumente o direito consuetudinário, no direito brasileiro a legislação, marcada pelas características da generalidade, imperatividade, e emanada de autoridade competente, ainda é a fonte jurídica por excelência.

Esse sistema, segundo Marinoni, é "não apenas fechado - autônomo e coerente -, mas também goza de plenitude” (2018, p. 48). Baseado em conceitos e conexões lógicas, sempre será possível suprir lacunas mediante a "construção criadora", de forma que os conceitos jurídicos são moldados com o fim de viabilizar a subsunção lógica de toda a qualquer situação concreta. (MARINONI, 2018, p. 48)

Importante destacar, ainda, que a busca da plenitude do sistema mediante a conceitualização tem o nítido propósito de assegurar previsibilidade e certeza na aplicação do direito, solucionando casos exclusivamente a partir de raciocínios lógicos, pautados em conceitos e princípios jurídicos-científicos. (MARINONI, 2018, p. 48)

Entretanto, neste novo modelo de sociedade globalizada, em que as relações se transformam em uma velocidade muito maior do que o Poder Legislativo é capaz de legislar, o Poder Judiciário tem se adaptado para enfrentar os litígios e entregar a prestação jurisdicional de 
acordo com os atuais padrões sociais, com o objetivo de dar efetivo acesso à população aos direitos fundamentais.

E o globalismo político e jurídico, por não ter capacidade de atuar direta e fisicamente no território, tem seus fenômenos caracterizados pela criação de estruturas pluriestratificadas, em que o objetivo é envolver os Estados em políticas públicas de impacto global, notadamente para envolver a tutela de direitos transindividuais, em que a soberania já não é mais capaz evitar as influências externas da atual realidade globalizada. (TEIXEIRA, 2011, p. 138)

O direito tradicional não cogitava os efeitos da globalização, de forma que suas fontes, tinham como único intuito suprir as necessidades do jurisdicionado diante de uma realidade menos complexa, considerando apenas as variáveis internas.

É importante destacar que o processo legislativo, gênese da fonte primária do direito, que é a lei, surge a partir da consciência dominante do povo, posto que os representantes do Poder Legislativo foram eleitos pelo povo, justamente para representar seus interesses.

Diante disto, as fontes de direito propostas se mostram insuficientes para regular a complexidade das relações jurídicas globalizadas.

E neste cenário, o Poder Judiciário tem sido visto como a resposta à insegurança jurídica, e pelo chamado ativismo judicial, muitas vezes tem se sobreposto aos demais poderes.

Inegável os avanços sociais (econômicos, tecnológicos e culturais) propulsionados pela globalização, que trouxeram crescentes possibilidades que no âmbito da tecnologia, da medicina, da comunicação, proporcionando o compartilhamento e aprimoramento de soluções para demandas universalizadas.

Todavia, também se mostra inconteste que a globalização fez com que as fontes do direito extrapolassem as barreiras político-geográficas, sendo o que o grande desafio do direito internacional privado é justamente compatibilizar a diversidade de legislações existentes, buscando, por isso, cada vez mais a uniformização do direito contratual dos diversos países, a fim de minimizar a barreira jurídica existente em virtude desta diversificação normativa.

Caso se mantenha o engessamento das fontes do direito, estaríamos a propor que o Poder Judiciário adote o "véu da ignorância" de Rawls (1997, p. 146-153), ignorando a universalização das culturas e o significativo aumento da complexidade das relações jurídicas e sociais, decorrentes da globalização. 


\section{A Reforma do Sistema Processual e o Acesso à Justiça}

Analisando a realidade da Justiça civil brasileira, Marinoni constata que o jurisdicionado tem grande dificuldade para prever como uma questão de direito será resolvida, e justifica essa dificuldade no fato de os juízes e tribunais não seguirem padrões mínimos de racionalidade ao decidirem (MARINONI, 2018, p. 69)

E o autor prossegue criticando um sistema judicial que, não obstante a intervenção da sua Corte Suprema, admite interpretações diferentes é completamente incapaz de gerir sua função de distribuir "justiça" nos casos concretos. Para o autor, o desrespeito aos precedentes das Cortes Superiores é porta aberta para desigual e aleatória distribuição da "justiça", com perversas consequências. (MARINONI, 2018, p. 70-71)

Outro ponto que se critica no judiciário brasileiro é exatamente a morosidade em se proferir decisões definitivas nos casos que lhe são levados.

Digno de nota que a obra "Acesso à Justiça" (1988), de Mauro Cappelletti e Bryant Garth, mesmo com dificuldades de definição, trouxe uma nova dimensão ao conceito de "acesso à justiça”. Neste sentido, lecionam os autores:

A expressão "acesso à Justiça" é reconhecidamente de difícil definição, mas serve para determinar duas finalidades básicas do sistema jurídico - o sistema pelo qual as pessoas podem reivindicar seus direitos e/ou resolver seus litígios sob os auspícios do Estado. Primeiro, o sistema deve ser igualmente accessível a todos; segundo, ele deve produzir resultados que sejam individual e socialmente justos. [...] Sem dúvida, a premissa básica será a de que a justiça social, tal como desejava por nossas sociedades modernas, pressupõe o acesso efetivo. (CAPPELLETTI; GARTH, 1988, p. 8)

E, para assegurar as finalidades básicas do sistema judiciário, os autores apresentam as chamadas ondas reformistas com a finalidade de viabilizar o acesso universal à justiça.

A primeira onda reformista proposta pelos autores se voltou aos meios de facilitar o acesso das classes menos favorecidas à Justiça, por intermédio da assistência judiciária aos pobres (1988, p. 31-49). 
A segunda onda demonstra a preocupação com a representação dos interesses difusos (chamados interesses coletivos ou grupais). As preocupações se voltam a mudar o cunho individualista do processo civil para uma concepção social e coletiva, a fim de satisfazer os interesses da sociedade. (1988, p. 49-67)

Por fim, a terceira onda de reformas prevê alterações das formas de procedimento, mudanças estruturais dos tribunais ou a criação de juizados especiais, a utilização de pessoas leigas, como julgadores e defensores, a utilização de mecanismos alternativos de resolução de conflitos. Nesta visão, os meios alternativos de solução dos conflitos devem ser prestigiados e estimulados, de forma que os jurisdicionados busquem a "justiça" fora dos tribunais, a fim de se obter uma decisão mais célere e eficaz. (1988, 67-73)

Importante rememorar que os mencionados autores advertem que o acesso à justiça não pode ser apenas formal:

De fato, o direito ao acesso efetivo tem sido progressivamente reconhecido como sendo de importância capital entres os novos direitos individuais e sociais, uma vez que a titularidade de direitos é destituída de sentido, na ausência de mecanismos para sua efetiva reivindicação. $\mathrm{O}$ acesso à justiça pode, portanto, ser encarado como requisito fundamental - o mais básico dos direitos humanos - de um sistema jurídico moderno e igualitário que pretenda garantir, e não apenas proclamar os direitos de todos. (CAPPELLETTI; GARTH, 1988, p. 1112)

Justamente com vistas a tentar corrigir, ou ao menos minimizar, esses problemas, viabilizar o acesso à justiça e garantir desenvolvimento econômico, o Banco Mundial, por meio do conhecido "Documento Técnico 319", apresentou em junho de 1996 uma proposta recomendando algumas reformas e providências aos Judiciários da América Latina e Caribe.

O diagnóstico e as diretrizes de referido documento serviram de inspiração para as reformas do Judiciário no Brasil e em outros países vizinhos.

Convém destacar que o objetivo geral do referido Documento Técnico 319 é promover o desenvolvimento econômico, de onde se constata que a proposta do Banco Mundial é de transformar o Poder Judiciário num garantidor dos princípios econômicos a serem implementados nos Estados alvos. 
No documento está consignado que "O Poder Judiciário é uma instituição pública e necessária que deve proporcionar resoluções de conflitos transparentes e igualitária aos cidadãos, aos agentes econômicos e ao estado". (DAKOLIAS, 1996, p. 7)

E verifica que:

\begin{abstract}
Um governo eficiente requer o devido funcionamento de suas instituições jurídicas e legais para atingir os objetivos interrelacionais de promover o desenvolvimento do setor privado, estimulando o aperfeiçoamento de todas as instituições societárias e aliviando as injustiças sociais.

Atualmente, o Judiciário é incapaz de assegurar a resolução de conflitos de forma previsível e eficaz, garantindo assim os direitos individuais e de propriedade.

A reforma do Judiciário faz parte de um processo de redefinição do estado e suas relações com a sociedade, sendo que o desenvolvimento econômico não pode continuar sem um efetivo reforço, definição e interpretação dos direitos e garantias sobre a propriedade. (DAKOLIAS, 1996, p. 10)
\end{abstract}

Com base neste documento, extrai-se, ainda, a tendência de reformas processuais de feição neoliberal, em que é feito um apelo para a reforma do Judiciário, no contexto de proteção ao capital. Tal apelo é possível ser verificado no seguinte trecho do Documento:

Os governos devem ser capazes de efetivar a aplicação das regras do jogo que foi criado; o judiciário, pode proporcionar este serviço garantindo direitos individuais e direitos sobre a propriedade.

Por sua vez, um consistente poder de coerção na execução das leis garante um ambiente institucional estável onde os resultados econômicos a longo prazo podem ser avaliados.

Neste contexto, um judiciário ideal aplica e interpreta as leis de forma igualitária e eficiente o que significa que deve existir: a) previsibilidade nos resultados dos processos; b) acessibilidade as Cortes pela população em geral, independente de nível salarial; c) tempo razoável de julgamento; d) recursos processuais adequados. (DAKOLIAS, 1996, p. 18)

O Banco Mundial entende que, para o livre manejo do capital especulativo, é necessária uma redução institucional da atuação do Poder Judiciário como defensor dos direitos e interesses individuais e coletivos, posto que, em muitos casos, são avessos aos interesses econômicos. 
Com efeito, verifica-se que a previsibilidade do sistema jurídico, e a garantia do cumprimento contratual são pontos essenciais para a atração do investidor estrangeiro num mundo globalizado.

Processos judiciais morosos e a possibilidade de descumprimento e revisão de contratos afastam o capital estrangeiro, que se aportará em países que lhe sejam mais "seguros".

Diante disso, observa-se, no Brasil, uma agenda criteriosa de cumprimento das diretrizes do Banco Mundial, com nítido intuito de atrair investimentos internacionais.

O advento da Emenda Constitucional 45 (2004), trouxe uma série de alterações constitucionais, dentre os quais podemos destacar a criação da Súmula Vinculante que vincula os demais órgãos do Poder Judiciário e a administração pública direta e indireta.

Outra alteração relevante desta Emenda Constitucional foi a criação do Conselho Nacional de Justiça, como um sistema disciplinar para controle dos Juízes e da atuação administrativa e financeira do Judiciário.

Após, vieram as reformas do revogado Código de Processo Civil que instituíram a súmula impeditiva de recurso, a improcedência in limine de demandas repetitivas, e regulamentaram a Súmula Vinculante e os institutos da Repercussão Geral e os Recursos Repetitivos (2006).

Por fim, podemos destacar a criação do Novo Código de Processo Civil (Lei 13.105/2015), que, dentre outras inovações, criou o sistema de precedentes vinculantes e estimulou ainda mais os métodos alternativos de resolução de conflitos.

Todos esses movimentos reformistas têm o claro intuito de adequar o ordenamento jurídico pátrio às expectativas do capital estrangeiro com vistas a atrair investimentos, assegurando um acesso à justiça mais efetivo.

\section{Sistema de precedentes brasileiro e a liberdade de decidir}

Pelas mudanças realizadas no sistema jurídico brasileiro, notadamente essas reformas influenciadas pelas balizas do Documento Técnico 319 do Banco Mundial, é possível verificar que o Brasil passa a se aproximar da família common law, não obstante a importância do direito positivo. (PORTELA, 2018, p. 51) 
Contudo, para alguns autores a adoção de institutos que tem origem no Direito anglosaxônico, não quer dizer que o Brasil tenha abandonado sua tradição de civil law para integrar-se ao common law. (CÂMARA, 2018, p. 56)

Para corroborar, Alexandre Freitas Câmara esclarece:

Significativo da ideia, aqui sustentada, de que a adoção dos precedentes como instituidores de padrões decisórios no Direito brasileiro não provoca uma saída do civil law para ingressar-se no common law está no fato de que, diferentemente do que se dá nos países de tradição anglo-saxônica, o precedente brasileiro precisou, para passar a ter eficácia vinculante, de disposição legal expressa neste sentido.

No common law não costuma existir lei a afirmar a eficácia vinculante dos precedentes. (CÂMARA, 2018, p. 58)

Os argumentos da duração razoável do processo, isonomia e segurança jurídica são os principais a fazer a defesa do que se tem chamado de direito jurisprudencial. (PORTELA, 2018, p. 51)

Entretanto, é importante destacar a advertência de Antônio Aurélio de Souza Viana e Dierle Nunes:

No direito brasileiro, por sua vez, é possível perceber uma colossal escassez técnico-teórica no manuseio dos precedentes, talvez em virtude da herança histórica que ainda situa o Brasil, de modo estanque, entre os países da tradição de civil law, acreditando-se, portanto, no protagonismo do legislador. (VIANA; NUNES, 2018, p. 181)

O crescente papel da jurisprudência pátria na aplicação do direito, sugere essa aproximação ao sistema common law, contudo, a inconstância da jurisprudência representava uma dificuldade de utilização do entendimento pretoriano. As reformas processuais levadas a cabo no Brasil serviram justamente para melhor estruturar os precedentes em prol da padronização decisória.

Note-se que o Código de Processo Civil de 2015 trouxe estruturação do sistema de precedentes, que foi desenhado para o reforço do direito jurisprudencial, mas sem perder de vista 
a almejada segurança jurídica e estandartização das decisões, garantindo uniformização e estabilização da jurisprudência.

O sistema de precedentes vinculantes é elogiado pela doutrina pátria, todavia, sempre se faz a advertência da necessidade de uniformização e estabilização das decisões judiciais:

[...] num sistema de precedentes, a orientação jurídica se torna efetivamente factível. Os advogados tem como cumprir o seu papel, que deixa de ser o de simplesmente arriscar - ainda que com custosa e convincente argumentação - a obtenção de uma decisão que, entre as várias que podem ser dadas, favoreça o seu cliente. Nesta dimensão, os advogados podem dar aos seus clientes uma previsibilidade acerca de uma dada situação jurídica ou de um possível litígio. Em suma: para que os advogados possam adequadamente exercer as suas funções e para que os cidadãos possam realmente ser orientados acerca dos seus direitos, o Judiciário deve ser confiável, ou melhor, as suas decisões devem ser previsíveis. (MARINONI, 2011, p. 178).

Com efeito, incumbe ao advogado indicar os riscos da propositura da demanda ao seu cliente, mas, não só isso, é necessário compreender que o operador do direito também tem o papel de auxiliar no aperfeiçoamento do precedente quanto às técnicas de formação e aplicação do precedente, a partir de um modelo coparticipativo.

Neste sentido, Cruz e Tucci observa que:

[...] a jurisprudência consolidada garante a certeza e a previsibilidade do direito e portanto, evita posteriores oscilações e discussões no que se refere à interpretação da lei. Os cidadãos baseiam as suas opções não apenas nos textos legais vigentes, mas, também, na tendência dos precedentes dos tribunais, que proporcionam àqueles, na medida do possível, conhecimento de seus respectivos direitos. (CRUZ E TUCCI, 2004, p. 296)

Como já mencionado, Marinoni constata que o jurisdicionado brasileiro tem grande dificuldade para prever como uma questão de direito será resolvida, diante do fato de os juízes e tribunais não seguirem padrões mínimos de racionalidade ao decidirem. E o autor critica o fato do sistema judicial admitir interpretações diferentes, o que o torna completamente incapaz de gerir sua função de distribuir "justiça” nos casos concretos. (MARINONI, 2018, p. 69-71) 
Barbosa Moreira destaca a necessidade de atribuir uma maior solidez e uniformidade da jurisprudência:

Trata-se, pura e simplesmente, de evitar, na medida do possível, que a sorte dos litigantes e afinal a própria unidade do sistema jurídico vigente fiquem na dependência exclusiva da distribuição do feito ou do recurso a este ou àquele órgão. (BARBOSA MOREIRA, 2012, p. 5)

Com efeito, a introdução do sistema de precedentes no arcabouço jurídico brasileiro teve o escopo, justamente, de aprimorar a previsibilidade do sistema jurídico e das decisões judiciais.

De outro lado, além da previsibilidade, outro aspecto imprescindível é a estabilidade, não apenas nos precedentes judiciais, mas, também, em relação à legislação.

A estabilidade é um carácter que visa uma maior solidez às decisões judiciais, permitindo que o jurisdicionado tenha maior confiança no Poder Judiciário.

Importante mencionar, ainda, que "o governo tem a responsabilidade abstrata de tratar o destino de cada cidadão com a mesma importância." (DWORKIN, 2014, p. 356)

E o mesmo autor continua:

O direito serve melhor sua comunidade quando é tão preciso e estável quanto possível, e isso se aplica particularmente ao direito fundamental, constitucional. Isso oferece uma razão geral para ligar a interpretação das leis e de uma constituição a algum fato histórico que seja, pelo menos em princípio, identificável e imune a conviç̧ões e alianças efêmeras. (DWORKIN, 2014, p. 438)

Diante disso, observa-se, no Brasil, uma agenda criteriosa de reformas legislativas com nítido intuito de atrair investimentos internacionais, simplificando procedimentos e almejando garantir segurança jurídica

Além disso, Dworkin já reconhecia a importância da estabilidade da interpretação das normas, arrazoando que uma comunidade política seria, a longo prazo, mais bem-sucedida, se 
assegurar a estabilidade da correta interpretação e não a decisões interpretativas. (DWORKIN, 2014, p. 439)

Neste trilhar, importante é a observação do Ministro Jorge Scartezzini, do Superior Tribunal de Justiça, no julgamento do REsp 227940/AL:

O Poder Judiciário deve ao jurisdicionado, em casos idênticos, uma resposta firme, certa e homogênea. Atinge-se, com isso, valores tutelados na ordem político-constitucional e jurídico material, com a correta prestação jurisdicional, como meio de certeza e segurança para a sociedade. Afasta-se, em consequência, o rigor processual técnico, no qual se estaria negando a aplicação do direito material, para alcançar-se a adequada finalidade da prestação jurisdicional, que é a segurança de um resultado uniforme para situações idênticas.

O crescente papel da jurisprudência pátria na aplicação do direito, sugere essa aproximação ao sistema common law, contudo, a inconstância da jurisprudência representava uma dificuldade de utilização do entendimento pretoriano. As reformas processuais levadas a cabo no Brasil serviram justamente para melhor estruturar os precedentes em prol da padronização decisória.

Entretanto, é importante ressaltar que o sistema jurídico deve ser visto com integridade e coerência, como adverte Ronald Dworkin:

Se uma instituição política só é coerente quando repete suas próprias decisões anteriores o mais fiel e precisamente possível, então a integridade não é coerência; é, ao mesmo tempo, mais e menos. A integridade exige que as normas públicas da comunidade sejam criadas e vistas, na medida do possível, de modo a expressar um sistema único e coerente de justiça e equidade na correta proporção. (DWORKIN, 2014, p. 264)

E a visão do direito como integridade exige que os julgadores reconheçam o direito como instituto estruturado por um conjunto coerente de princípios sobre a justiça, equidade e devido processo legal, aplicando-o nos novos casos que lhes são apresentados, de modo que cada jurisdicionado receba a resposta justa e equânime segundo as mesmas normas. (DWORKIN, 2014, p. 291) 
Neste sentir, coerência está ligada à consistência lógica que cada decisão deve manter com casos semelhantes e integridade à exigência de que os juízes construam seus argumentos de modo integrado ao Direito como um todo (TOVAR, 2018, p. 256).

E Didier adverte que se deve "compreender o Direito como um sistema de normas, $e$ não um amontoado de normas. O dever de integridade é nesse sentido uma concretização do postulado da unidade do ordenamento jurídico". (DIDIER, 2015, p. 395)

Ademais, dissertando sobre as técnicas do sistema de precedentes, Mancuso observa:

O elemento comum a tais técnicas processuais é que por elas se busca imprimir racionalidade ao sistema e otimizar a eficácia da resposta jurisdicional, a qual, ao se expandir em modo panprocessual, ou até por vez até ao interno da inteira coletividade ou de um segmento dela, impregna-se, em boa medida, das notas de generalidade, abstração e impessoalidade que cercam a norma legal. (grifos no original) (MANCUSO, 2016, p. 219-220)

Deste modo, o objetivo de imprimir racionalidade e otimizar a eficácia, em linhas gerais, pretende justamente fornecer ao jurisdicionado uma melhor reposta e um acesso à justiça mais efetivo.

Contudo, uma advertência que deve ser feita é que essa estandardização não pode ser levada a efeito pela simples reprodução mecânica de decisões, pois, tão importante quanto a quantidade de decisões é a qualidade da prestação jurisdicional.

Com efeito, a simples adoção do sistema de precedentes, com a mera transcrição ementas para fundamentar decisões não é suficiente para assegurar a almejada coerência e integridade do sistema jurídico, é imprescindível que se faça a adequação pormenorizada do precedente ao caso concreto, especialmente em tempos atuais em a pandemia que estamos atravessando exige uma relativização e uma reinterpretação das situações jurídicas de outrora.

Em momento de calamidade pública, mostra-se ainda mais necessário que o julgador analise casuisticamente se o precedente invocado ainda permanece aplicável ao caso concreto, realizando a verificação pormenorizada se o precedente se aplica ao caso em julgamento 
(distinguishing ${ }^{l}$ ), ou se o precedente continua sendo justo à resolução daquele problema (overruling ${ }^{2}$ ).

Neste aspecto, a observação de Streck e Abboud:

É prática recorrente - afinal não há sentença ou acórdão que assim não proceda - a mera menção de ementas de acórdãos, utilizados como pautas gerais nas decisões. Tal circunstância acarreta um enfraquecimento da força persuasiva da doutrina, deixando-se a tarefa de atribuição do sentido das leis aos tribunais, fenômeno que é retroalimentado por uma verdadeira indústria de manuais jurídicos, que colacionam ementários para servirem de pautas gerais (STRECK; ABBOUD, 2014, p. 78)

De outro lado, também é possível verificar que o sistema de precedentes vem mitigar a liberdade de proferir decisões dos julgadores segundo sua própria consciência, posto que, no atual sistema, estão vinculados a decidir de acordo com os precedentes de observância obrigatória, o que acaba por gerar uma antítese à tradição do cartesianismo ${ }^{3}$, para quem a verdade estaria no sujeito e não na lei (STRIQUER SOARES, 2017, p. 348).

Todavia, "o precedente representa, em verdade, um ponto de partida para a análise $e$ julgamento do caso concreto e não uma restrição ao poder de julgar" (PORTO, 2006, p. 766).

Assim, oportuna a conclusão de Leonardo Zehuri Tovar:

(i) não é possível abrir mão da qualidade das decisões - e de sua fundamentação - em prol de uma celeridade cujas causas são externas à própria atividade dos tribunais; (ii) o julgador não é um mero reprodutor de textos legais; (iii) é absolutamente inadequado separar questões de fato e de direito, estandardizando casos, com a promoção do esquecimento do caso concreto; e, (iii) obviamente, decidir não é escolher! (TOVAR, 2018, p. 220)

Por fim, não obstante a mitigação da liberdade decisória, o atual sistema privilegia o direito como integridade e estabelece a necessidade de sistema coerente e estável.

\footnotetext{
${ }^{1}$ Quando o julgador confronta o caso concreto e o precedente, verificando se se tratam de situações análogas.

2 Quando o julgador decide que o precedente não é mais adequado à resolução justa da demanda, pois o entendimento foi ultrapassado.

3 "Dentro da tradição do cartesianismo, portanto, a verdade está no juiz, no sujeito que decide, tendo sua intuição como fonte da verdade." (STRIQUER SOARES, 2017, p. 356)
} 
Desta forma, embora possa se falar em uma limitação à liberdade decisória do julgador, frente à obrigatória observância ao precedente, veja-se que é possível (e necessário) que o julgador faça uma devida adequação do caso concreto com o precedente, usando conforme o caso, as ferramentas do distinguishing e do overruling.

Para correta aplicação do precedente é necessária a utilização da atividade interpretativa, e esta atividade precisa da definição de um método, sob pena de ser chancelada uma solução mecânica e subsuntiva, na qual a orientação pretoriana ganharia contornos gerais de norma, no entanto, o melhor é dizer que não há clareza que dispense atividade interpretativa (TOVAR, 2018, p. 258).

\section{Considerações finais}

O estudo demonstrou as intensas e profundas alterações que as relações sociais têm passado em razão da globalização, e a forma com que tem atingido o sistema jurídico brasileiro, demonstrando, assim, a necessidade de se repensar pontos importantes do sistema processual pátrio.

O avanço tecnológico e o crescimento e desenvolvimento exponencial das relações sociais fez com que muitas mudanças ocorressem, sendo, proporcionalmente, necessário que o Direito também acompanhe esse fluxo, providenciando maneiras de se enfrentar essas evoluções.

A proposta do presente trabalho foi desenvolvida mediante a devida apresentação das reformas ocorridas no sistema processual brasileiro em razão das recomendações do Banco Mundial, expondo as necessidades e possibilidades das reformas para acompanhar todo o efeito desse fluxo de globalização e assegurar o efetivo acesso à justiça e o desenvolvimento econômico do país.

Outrossim, apresentou-se linhas gerais do sistema de precedentes, como método de corroborar a previsibilidade e estabilidade às decisões judiciais, e como um importante instrumento para assegurar a integridade, coesão e coerência do direito. Analisou-se, também, os impactos que a implantação dos precedentes vinculantes trouxe na liberdade decisória.

Através de uma proposta objetiva, o presente trabalho analisou esse (novo) contexto globalizado que deu azo à reforma do sistema jurídico brasileiro como medida apta a ser tomada para proporcionar a almejada segurança jurídica. 
Verificou-se que, não obstante tenha ocorrido mitigação na liberdade de decidir, posto que julgador precisa observar o que foi decidido anteriormente em casos de precedentes vinculante, o atual sistema privilegia o direito como integridade e estabelece a necessidade de um sistema coerente e estável.

Desta forma, embora haja uma limitação à liberdade decisória, viu-se que é necessário que o julgador faça uma devida adequação do caso concreto com o precedente, usando conforme o caso, as ferramentas do distinguishing e do overruling, para a correta aplicação do precedente.

\section{Referências Bibliográficas}

BARbosa MOREIRA, José Carlos. Comentários ao Código de Processo Civil. 16. ed. rev. atual. e ampl. Rio de Janeiro: Forense, 2012. v. 5.

BELLINETTI, Luiz Fernando, Tutela Transindividual como Instrumento Democrático para Implementar a Defesa do Consumidor no Mundo Globalizado. In: SOARES, Marcos Antônio Striquer et al. (org.). Estudos em Direito Negocial e Democracia. Birigui: Boreal Editora, 2017.

CÂMARA, Alexandre de Freitas. Levando padrões decisórios a sério. 1. ed. São Paulo: Atlas, 2018.

CAPPELlETTI, Mauro; GARTH, Bryant. Accesso à Justiça. Trad.: Ellen Gracie Northfleet. Porto Alegre: Sergio Antonio Fabris Editor, Porto Alegre. 1988.

CRUZ E TUCCI, José Rogério. Precedente judicial como fonte de direito. São Paulo: Ed. RT, 2004.

DAKOLIAS, Maria. Banco Mundial: Documento Técnico número 319: elementos para a reforma. $1996 . \quad$ Disponível em $\langle$ https://www.anamatra.org.br/attachments/article/24400/00003439.pdf $>$ aceso em 8.12.2019, às $17: 10$.

DIDIER JÚNIOR, Fredie. Sistema brasileiro de precedentes judiciais obrigatórios e os deveres institucionais dos tribunais: uniformidade, estabilidade, integridade e coerência da jurisprudência. In: DIDIER, JÚNIOR et al. (cood.). Precedentes. Coleção grandes temas do novo CPC. v. 3. Salvador: JusPodivm, 2015.

DWORKIN, Ronald. O império do direito. Tradução: Jeferson Luiz Camargo; revisão técnica: Gildo Sá Leitão Rios. 3. ed. São Paulo: Martins Fontes, 2014.

FARIA, José Eduardo. O Estado e o direito depois da crise. 2 ed. São Paulo: Saraiva, 2017. 
MANCUSO, Rodolfo de Camargo. Sistema brasileiro de precedentes: natureza, eficácia, operacionabilidade. 2. ed. rev. atual. e ampl. São Paulo: Editora Revista dos Tribunais, 2016.

MARINONI, Luiz Guilherme. A ética dos precedentes: justificativa do novo CPC. 3 ed. rev. e atual. São Paulo: Thomson Reuters Brasil. 2018.

MARINONI, Luiz Guilherme. Precedentes obrigatórios. 2 ed. rev. e atual. São Paulo: Revista dos Tribunais. 2011.

PORTELA, João Filho de Almeida. O precedente obrigatório e o dilema entre garantias constitucionais e a estandartização do direito. Salvador: Editora JusPodivm, 2018.

PORTO, Gilberto Sérgio. Sobre a common law e o precedente judicial. In: MARINONI, Luiz Guilherme (org.). Estudos de direito processual civil. Homenagem ao Professor Egas Dirceu Moniz de Aragão. São Paulo: Revista dos Tribunais, 2006.

RAMOS, César Agusto. O liberalismo político e seus críticos. Crítica: Revista de Filosofia. Londrina: Universidade Estadual de Londrina. Vol. 10, número 32, p. 229-264, out. 2005.

RAWLS, John. Uma teoria da justiça. Tradução de Almiro Pisetta e Lenita Maria Rímoli Esteves. São Paulo: Martins Fontes, 1997.

STRECK, Lenio; ABBOUD, Georges. O que é isto - o precedente judicial e as súmulas vinculantes? Porto Alegre: Livraria do Advogado, 2014.

STRIQUER SOARES, Marcos Antônio. A decisão judicial em Hans Kelsen e a tradição do cartesianismo. Revista Brasileira de Estudos Políticos. Belo Horizonte: Universidade Federal de Minas Gerais, n. 114, pp. 345-387, jan./jun. 2017.

TEIXEIRA, Anderson Vichinkeski. Teoria pluriversalista do direito internacional. São Paulo: Editora WMF Martins Fontes, 2011.

TOVAR, Leonardo Zehuri. Por uma teoria da decisão judicial: a discricionariedade decisória e a busca por respostas constitucionalmente adequadas. $325 \mathrm{f}$. Tese (Doutorado em Direitos e Garantias Fundamentais) - Programa de Pós-Graduação em Direitos e Garantias Fundamentais, Faculdade de Direito de Vitória, Vitória, 2018.

VIANA, Antônio Aurélio de Souza; NUNES, Dierle. Precedentes: a mutação no ônus argumentativo. Rio de Janeiro: Forense, 2018. 